\title{
Taxon-specific tidal resuspension of protists into the subtidal benthic boundary layer of a coastal embayment
}

\author{
Jeff Shimeta $^{1,2,3, *}$, John D. Sisson ${ }^{1}$

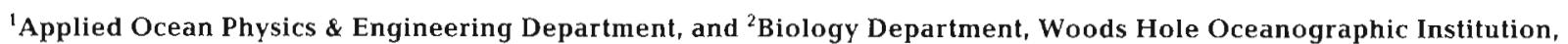 \\ Woods Hole, Massachusetts 02543, USA \\ ${ }^{3}$ Biology Department, Franklin \& Marshall College, PO Box 3003, Lancaster, Pennsylvania 17604-3003, USA
}

\begin{abstract}
Sediment resuspension has widespread effects on microbial processes, primary and secondary production, and nutrient cycles, but its influence on protists other than microalgae is largely unknown. Distributions and abundances of protists in subtidal benthic boundary layers (BBL), in particular, are poorly known. We measured vertical profiles of protists in the BBL and underlying sediment at a subtidal silty site in Buzzards Bay, Massachusetts, USA, to determine cell-resuspension patterns. Tidal flow produced maximal bottom shear velocities of 1.4 to $2.2 \mathrm{~cm} \mathrm{~s}^{-1}$ Near-bottom turbidity increased during each slack tide, when the suspended load settled, and it decreased during tidal exchange, presumably after a thin veneer of sediment resuspended from the sediment-water interface (SWI) and mixed into the upper water column. Tidal periodicities in protistan vertical profiles were taxon-and functional-group specific. Heterotrophic nanoflagellates (HNan) and ciliates, including scuticociliates, oligotrichs, and hypotrichs of the genera Euplotes and Urostrongylum, showed periodicities in distribution consistent with cycles of resuspension and deposition. BBL concentrations of HNan and scuticociliates were elevated during tidal exchange by factors of $\leq 2.1$ and 4.6 , respectively, within $5 \mathrm{~cm}$ of the SWI; oligotrichs were found consistently in the BBL but were in the sediment only during slack tide; Euplotes was present consistently in the sediment but was in the BBL only during tidal exchange. Total resuspended cells in the bottom $1 \mathrm{~m}$ were of the order $10^{8}$ to $10^{9} \mathrm{HNan} \mathrm{m}^{-2}$ and $10^{5}$ to $10^{6}$ ciliates $\mathrm{m}^{-2}$, and in some cases the measured cell disappearance from surficial sediment during tidal exchange balanced the increase in the BBL. In contrast, pigmented nanoflagellates, pennate diatoms, and ciliates, including karyorelictids and other hypotrichs, maintained constant profiles throughout tidal cycles. Specificity of results among protistan groups might be due to behavioral adaptations such as depth zonation in the sediment, associations with particles, and vertical migration. We know of no other documentation in the field of cyclical emergence of heterotrophic protists and re-entry into sediment. Our data suggest complex taxon-specific linkages between sedimentary and water-column protistan communities that may be controlled by flow in the BBL, potentially influencing food-web dynamics.
\end{abstract}

KEY WORDS: Protists - Benthic boundary layer - Resuspension · Benthic-pelagic coupling $\cdot$ Buzzards Bay

\section{INTRODUCTION}

Resuspension of sedimentary material plays an integral role in coupling the benthos and plankton by transferring nutrients, detritus, and organisms to the water column. Resuspended microalgae can contribute

\footnotetext{
- Address for correspondence: Biology Department, Franklin \& Marshall College, PO Box 3003, Lancaster, Pennsylvania 17604-3003, USA.E-mail: j_shimeta@acad.fandm.edu
}

greatly to phytoplankton stocks and primary productivity in estuaries, and resuspended cells and detritus can augment secondary productivity of suspension feeders (Roman \& Tenore 1978, Baillie \& Welsh 1980, de Jonge \& van Beusekom 1992). The subtidal benthic boundary layer (BBL) is most directly influenced by resuspension, and in this zone there is an active food web, particularly involving microbes (Townsend et al. 1992, Ritzrau et al. 1997). Boundary-layer flow and resuspension may have large effects on the BBL microbial community and its 
activities, e.g. by increasing bacterial concentrations, cell sizes, and growth rates (Wainright 1987, 1990, Ritzrau \& Graf 1992, Ritzrau 1996).

Influences of resuspension on protistan communities, other than microalgae, are largely unknown. The issue was addressed only by Wainright (1987, 1990), who reported increases in the biovolume of total suspended heterotrophic protists after eroding box cores of sediment in a laboratory flume.

Field sampling of protists, especially heterotrophs, has been rare in subtidal near-bottom water (Novitsky 1990, Townsend et al. 1992), and studies of heterotrophs other than forams and amoebae in subtidal sediments are few (e.g. Bak \& Nieuwland 1989, Alongi 1990, Hondeveld et al. 1994). Abundances and activities of protists in the BBL, and their distinctiveness from or linkages with the sedimentary community, are largely uncharacterized.

We measured vertical distributions of protists in the subtidal BBL and sediment of Buzzards Bay, Massachusetts, USA, where material resuspension has been demonstrated previously (Rhoads 1973, Roman \& Tenore 1978). Samples taken repeatedly throughout tidal cycles, with resolution in the BBL to within $1 \mathrm{~cm}$ of the sediment-water interface (SWI), revealed periodicities in vertical cell profiles consistent with a cycle of resuspension and deposition, and the effects were specific to certain protistan taxa and functional groups.

\section{METHODS}

We collected samples during spring tides at the $15 \mathrm{~m}$ deep Weepecket Island site $\left(41^{\circ} 31.25^{\prime} \mathrm{N}, 70^{\circ} 45.7^{\prime} \mathrm{W}\right)$ in Buzzards Bay, a nonestuarine embayment (see maps in Banta et al. 1995). This position is within the central silty region of the bay (Moore 1963), and it is at or very near sites of previous studies of tidal resuspension and benthic-pelagic coupling (Rhoads et al. 1975, Roman 1978, 1980, Roman \& Tenore 1978) as well as sediment biogeochemistry (Rowe \& McNichol 1991, Banta et al. 1995).

An InterOcean Systems S4 current meter and a SeaTech transmissometer $(5 \mathrm{~cm}$ path length, with a coupled ParoScientific pressure sensor and TattleTale data logger) were each moored $1 \mathrm{~m}$ above bottom (m.a.b.), ca $80 \mathrm{~m}$ from the Weepecket site coordinates. Moorings were positioned so they were never directly upstream or downstream of the site coordinates at the times of water and sediment collection. On days that we collected samples throughout the tidal cycle, we took vertical profile casts with another SeaTech transmissometer (25 cm path length).

We collected water samples throughout tidal cycles on 30 July and 26 September, 1996, with a benthic

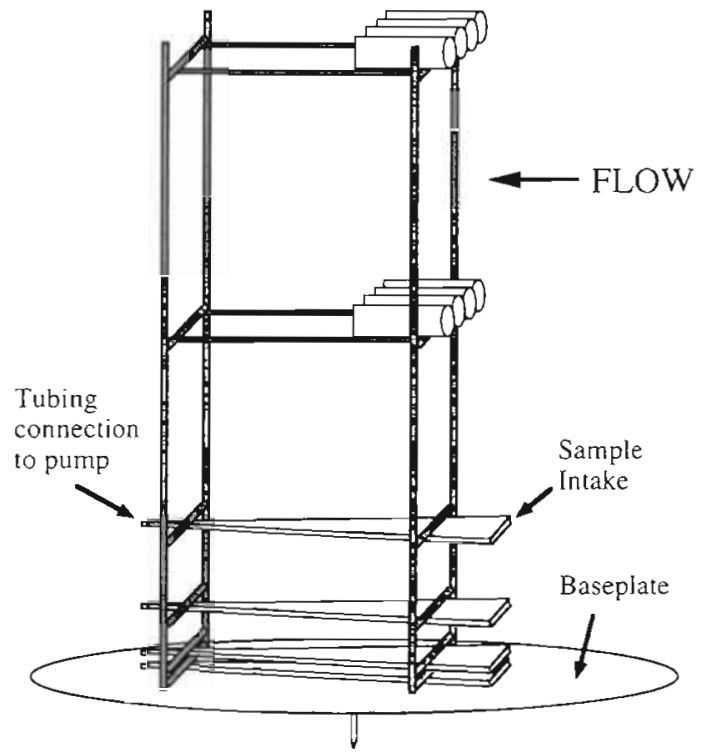

Fig. 1. Benthic boundary-layer water sampler. See text for description

boundary-layer sampler (Fig. 1) consisting of a vertical rack of intakes attached by silicone tubing $(0.6 \mathrm{~cm}$ inner diameter) to a peristaltic pump aboard ship. Before each sampling, SCUBA divers positioned the $1 \mathrm{~m}$ diameter aluminum base plate flush with the SWI to prevent artifactual resuspension underneath the intakes, which faced directly into the ambient flow. The lower intakes were flat polycarbonate funnels with $0.5 \mathrm{~cm}$ vertical openings, positioned $15 \mathrm{~cm}$ behind the leading edge of the base plate, and centered at $0.75,5,10$, and $20 \mathrm{~cm}$ above bottom. All intakes were pumped simultaneously to collect 11 of sample at $400 \mathrm{ml} \mathrm{min}^{-1}$ (tubing $R e=1400$, thus laminar flow). Face velocities differed depending on the widths of the intakes, which were constructed individually to create a logarithmic profile of sampling velocities (as low as $0.25 \mathrm{~cm} \mathrm{~s}^{-1}$ at $0.75 \mathrm{~cm}$ ). Three sets of intake funnels of different widths were interchanged depending on the ambient flow speeds at the time of sampling (monitored from the surface with an acoustic Doppler current profiler), so that intake velocities were ca 20 to $50 \%$ below ambient to avoid entraining fluid from outside the target depth interval. Centered at 50 and $100 \mathrm{~cm}$ above bottom were $9.5 \mathrm{~cm}$ diameter polycarbonate pipes that were capped manually on both ends by divers to enclose water samples. On 26 September, however, strong swell prevented tethering the sampler to the ship by the intake tubing, so a third set of manually capped pipes $13.8 \mathrm{~cm}$ diameter) was attached to the sampler, centered at $8.5 \mathrm{~cm}$ above bottom. Samples for protistan counts were preserved with $1 \%$ glutaraldehyde.

Sediment cores (3.8 cm diameter) were taken manually by divers $8 \mathrm{~m}$ from the water sampler in a direction 
normal to the flow while the sampler was deployed. Cores were transported gently to the surface while being maintained in a vertical orientation. Overlying water was carefully removed with a Pasteur pipet to $<0.1 \mathrm{~cm}$ of the sediment surface, with great care taken not to resuspend any material. Only cores with level surfaces that appeared undisturbed throughout all steps of handling were subsequently used for samples. Using a calibrated piston device (Fuller \& Butman 1988), the sediment was raised flush by eye with the core tube to identify the sediment-water interface, from which it was extruded (with accuracy $\approx 0.01 \mathrm{~cm}$ ) and sliced into depth sections of $0-0.2,0.5-1.0,1.5-2.0$, $4.5-5.0$, and $9.5-10 \mathrm{~cm}$. Sections were sliced with a stiff plastic card and rinsed with $0.2 \mu \mathrm{m}$ filtered sea water into a funnel over sample containers, then preserved for protistan counts with $1 \%$ glutaraldehyde by volume.

Characterization of deposited and suspended sediment was made from unpreserved samples. Total suspended mass was measured from portions of water samples that were filtered onto preweighed $\mathrm{GF} / \mathrm{F}$ filters, rinsed with distilled water, dried, and reweighed. Sediment grain size was determined by wet sieving into size fractions and weighing dry (Wheatcroft \& Butman 1997). Sediment porosity was determined by weighing depth sections before and after drying to determine percent water content (converted to volume fraction).

We extracted protists from sediment samples by modified protocols from Starink et al. (1994) and Epstein (1995). Density gradients were formed in $16 \mathrm{ml}$ centrifuge tubes, using $9 \mathrm{ml}$ of $50 \%$ Percoll in doublesalinity sea water, centrifuged at $38800 \times g$ for $30 \mathrm{~min}$. The sample was diluted to $0.05 \mathrm{~cm}^{3}$ sediment $\mathrm{ml}^{-1}$, vortexed at medium strength for $10 \mathrm{~s}$, and allowed to settle for $15 \mathrm{~s}$ before loading $2 \mathrm{ml}$ onto the Percoll gradient. The sample was extracted once by centrifuging at $4300 \times g$ for $15 \mathrm{~min}$ in a swinging-bucket rotor, and the supernatant was retained for microscopy.

To count nanoflagellates and diatoms, water samples and extracted sediment samples were stained with $50 \mu \mathrm{g} \mathrm{ml}^{-1}$ DAPI and observed on $0.8 \mu \mathrm{m}$ pore size Nuclepore filters by epifluorescence microscopy under UV excitation (Porter \& Feig 1980), switching to blue excitation to identify pigmented cells by chlorophyll fluorescence. To count ciliates, water samples were settled in $100 \mathrm{ml}$ Utermohl chambers overnight with $0.004 \%$ Nigrosin Black and examined in an inverted compound microscope with phase contrast. Sediment samples were each settled for $5 \mathrm{~d}$ after adding the Percoll supernatant from one centrifuge-tube extraction to an Utermohl chamber and diluting to $100 \mathrm{ml}$ with deionized water and Nigrosin Black. Sedimentary ciliates were tentatively identified only by gross morphology according to drawings in Carey (1992). Samples from
30 July at $5 \mathrm{~cm}$ above bottom were only examined for nanoflagellates and diatoms, and those from $10 \mathrm{~cm}$ above bottom were not examined.

Vertical profiles of cell concentrations in the BBL and the sediment were tested separately by ANOVA (Systat 5.2.1) to determine differences among depths and among tidal stages. Sediment data were analyzed by 2-way repeated measures ANOVA (individual cores as replicates with depth as the repeated variable). In cases with significant differences among tidal stages or significant tidal stage $x$ depth interactions, Bonferroni-adjusted pairwise comparisons were also made. Because the water sampler took only 1 sample at each depth during each deployment, we analyzed BBL profiles from 30 July by randomized block ANOVA without replicates and no pairwise comparisons, while profiles from 26 September were merely assessed visually because of missing blocks.

\section{RESULTS}

Sediment at the site was predominantly silt. The total sediment mass residing in the $<25 \mu \mathrm{m}$ fraction was $>50 \%$ (Table 1 ). The surficial sediment (top $0.2 \mathrm{~cm}$ ) had a porosity $\geq 90 \%$ and appeared highly unstable to divers, being easily eroded by nearby movements or slight contact.

Current velocity measured at 1 m.a.b. was strongly dominated by tidal forcing and highly rectified along the long axis of the bay running NE-SW, turning counter-clockwise during the tidal cycle (Fig. 2). Maximal resultant speeds during tidal exchange ranged from 25 to $40 \mathrm{~cm} \mathrm{~s}^{-1}$, corresponding to shear velocities (u.) of 1.4 to $2.2 \mathrm{~cm} \mathrm{~s}^{-1}$ (assuming a bottom drag coefficient of $3 \times 10^{-3}$, Sternberg 1968).

Light transmittance measured over a several-day period at $1 \mathrm{~m}$.a.b. fell toward the end of each slack tide and increased during the ensuing tidal exchange (Fig. 2). This pattern was consistent with a turbidity cloud settling during slack tide, then mixing higher

Table 1 Disaggregated grain size distribution (mass fraction) in the top 2 depth sections of sediment

\begin{tabular}{|lcc|}
\hline $\begin{array}{l}\text { Size class } \\
(\mu \mathrm{m})\end{array}$ & $\begin{array}{c}0.0-0.2 \mathrm{~cm} \\
\text { depth section } \\
( \pm \mathrm{SD}, \mathrm{n}=8)\end{array}$ & $\begin{array}{c}0.5-1.0 \mathrm{~cm} \\
\text { depth section } \\
( \pm \mathrm{SD}, \mathrm{n}=4)\end{array}$ \\
\hline$\geq 250$ & $0.040( \pm 0.033)$ & $0.012( \pm 0.0078)$ \\
$125-249$ & $0.027( \pm 0.014)$ & $0.0075( \pm 0.0042)$ \\
$63-124$ & $0.14( \pm 0.020)$ & $0.13( \pm 0.015)$ \\
$38-62$ & $0.17( \pm 0.018)$ & $0.18( \pm 0.025)$ \\
$25-37$ & $0.11( \pm 0.020)$ & $0.11( \pm 0.010)$ \\
$<25$ & $0.52( \pm 0.027)$ & $0.56( \pm 0.048)$ \\
\hline
\end{tabular}



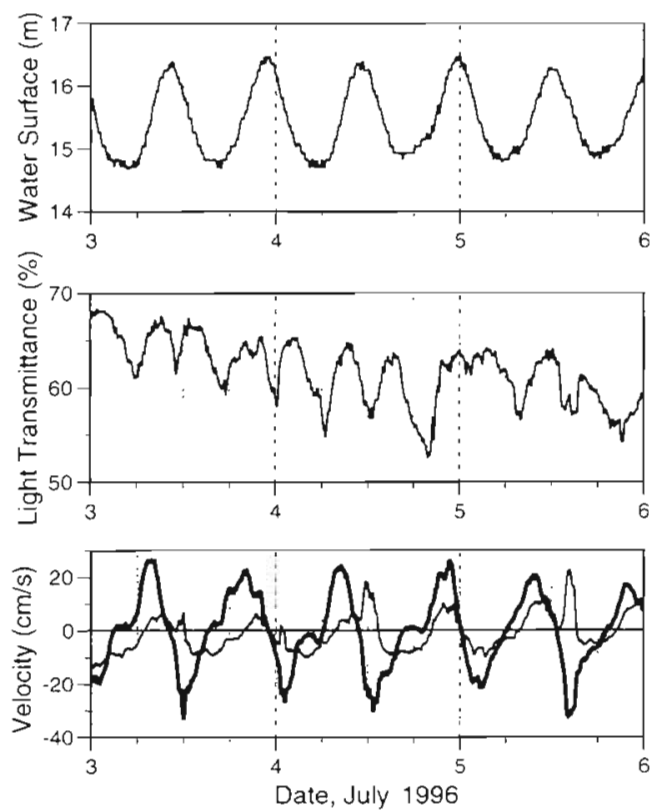

Fig. 2. Record of tide level (water surface height), light transmittance ( 1 m.a.b.) and velocity ( 1 m.a.b.) over 3 d. Transmittance dropped at the end of each slack-tide period. The major-axis component of flow variation (thick line) was on

$20.0^{\circ}$; minor-axis component (thin line) was on $290.0^{\circ}$

into the water column as flow speed increased, thereby rendering the $\mathrm{BBL}$ clearer despite any addition of material resuspended from the bed. Of the 2 dates on which we sampled protists repeatedly throughout the tidal cycle, this turbidity pattern was most consistent on 30 July (Fig. 3). On both of these dates, nonetheless, water-column profiles of light transmittance (Fig. 4) were consistent with a cycle of settling and upward mixing. Profiles showed that turbidity consistently increased toward the bed, but during slack tide the near-bottom turbidity layer was confined closer to the bottom (i.e. the lutocline was lowest at slack tide). Filtered seston collected on 26 September was elevated to $55 \mathrm{mg} \mathrm{l}^{-1}$ during slack tide at $8.5 \mathrm{~cm}$ above the bed (Fig. 5). Surface temperature was 21 and $18^{\circ} \mathrm{C}$ on 30 July and 26 September, respectively, and on both dates a thermocline was present at $5 \mathrm{~m}$ depth.

The tidally periodic changes in near-bottom turbidity were the result of local processes of alternating settling and re-entrainment into the upper water column, as opposed to advection of differing water masses past the site. Light transmittance was strongly correlated with flow speed during the acceleration phase, and it did not fall until the end of the deceleration phase (Fig. 6), suggesting a local settling event at slack tide as opposed to predominant advection. The suspended material and cells that we collected in the BBL were certainly undergoing some advection and, if recently resuspended, they derived from somewhere upstream of our site. Nonetheless, using the velocity records at 1 m.a.b. and assuming a spatially uniform flow field, reconstructions of the flow path leading to our site suggested that the water we sampled had been restricted to the central silty region of the bay throughout the day (Fig. 7). We assumed that the bottom sediments and protistan communities were homogeneous horizontally throughout the center of the bay (cf. Moore 1963) and
A. 30 July, 1996
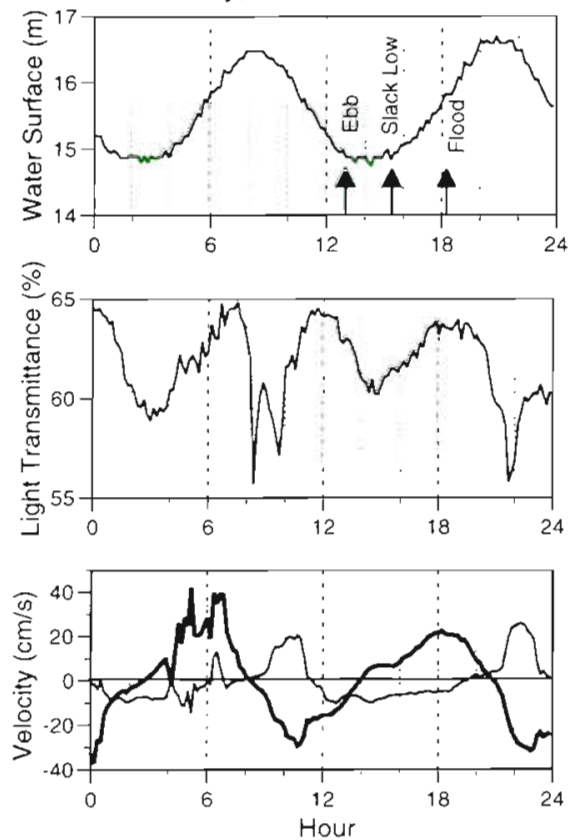

B. 26 Sept., 1996
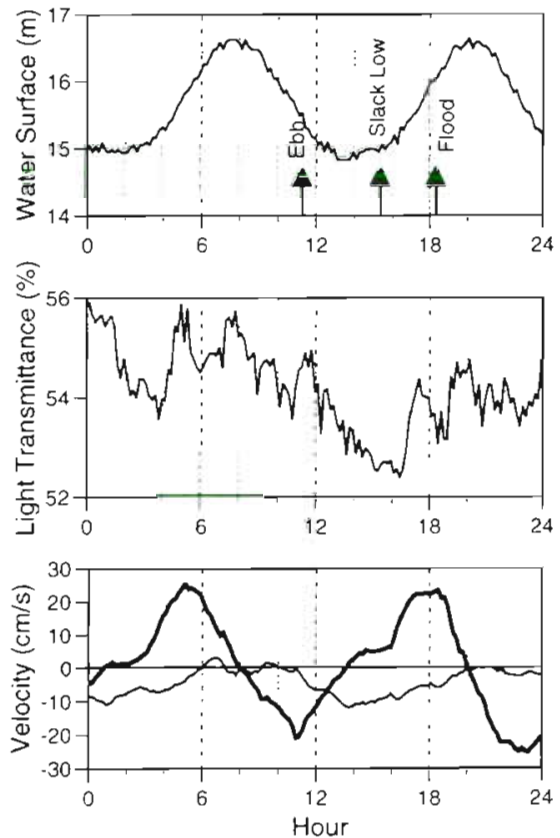

Fig. 3. Tide level (water surface height), light transmittance ( $1 \mathrm{~m}$.a.b.) and velocity $(1 \mathrm{~m}$.a.b.) on 2 dates during which the benthic boundary layer and sediment were sampled for protists repeatedly throughout the tidal cycle. Arrows in top panels identify the sample times labeled 'Ebb': 'Slack Low', and 'Flood' in subsequent figures and tables. On 30 July and 26 September, respectively, the major axis of flow (thick line) was on $45.3^{\circ}$ and $41.8^{\circ}$, the minor axis (thin line) was on $315.3^{\circ}$ and $311.8^{\circ}$ 


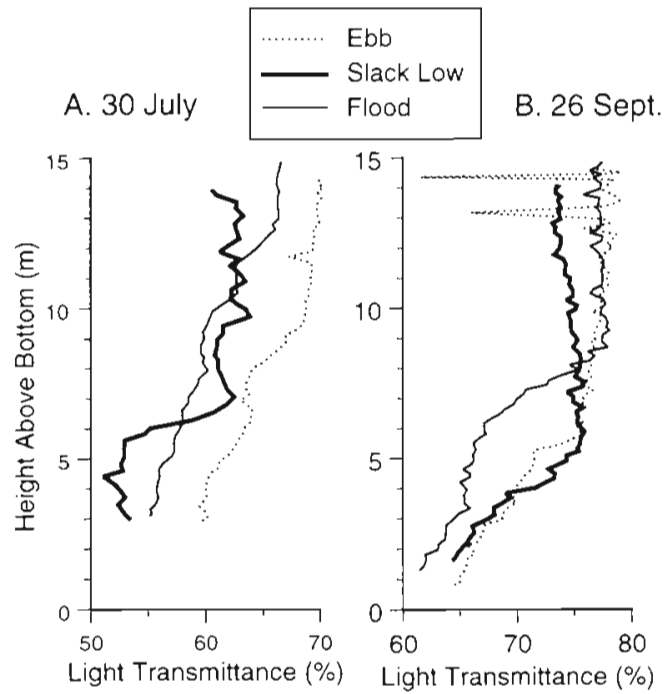

Fig. 4. Transmissometer casts corresponding to the sampling times indicated in Fig. 3

therefore that the suspension we sampled at the study site was the result of processes identical to those occurring at the site. There was significant flow normal to the principle axis of tidal exchange, especially the net advection to the southeast on 26 September (Fig. 7), so we had not merely resampled the same water as it oscillated back and forth.

The turbidity dynamics observed in Fig. 2 were used to schedule times for sampling protists during the expected maximal and minimal near-bottom turbidity (labeled roughly as 'ebb', 'slack low', and 'flood' on Fig. 3). On the 2 dates that we sampled protists, tidal periodicity of cell profiles differed among taxonomic

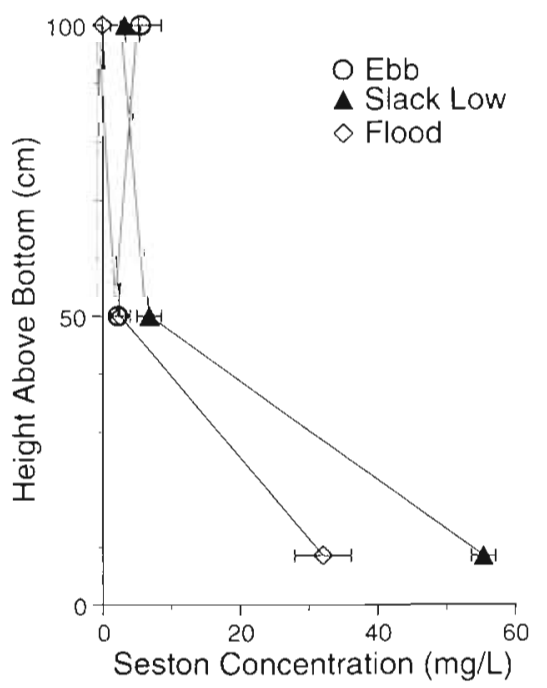

Fig. 5. Profiles of seston (total GF/F-filtered particulates) on 26 September, with sampling times corresponding to those shown in Fig. 3B
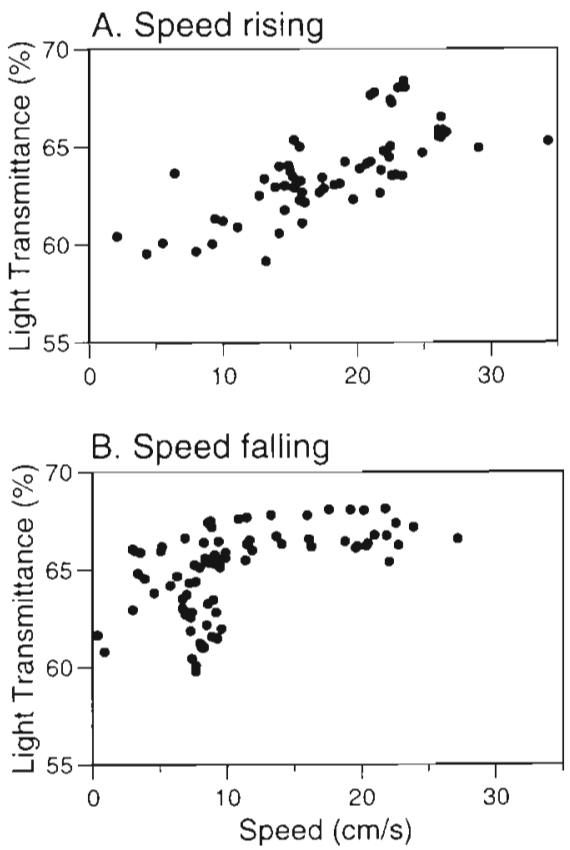

Fig. 6. Light transmittance (1 m.a.b.) as a function of flow speed on 3 July (data from Fig. 2). (A) Accelerational phases of the tidal cycle (Pearson correlation coefficient $=0.73, p<$ 0.001 ). (B) Decelerational phases and ensuing slack tide periods combined

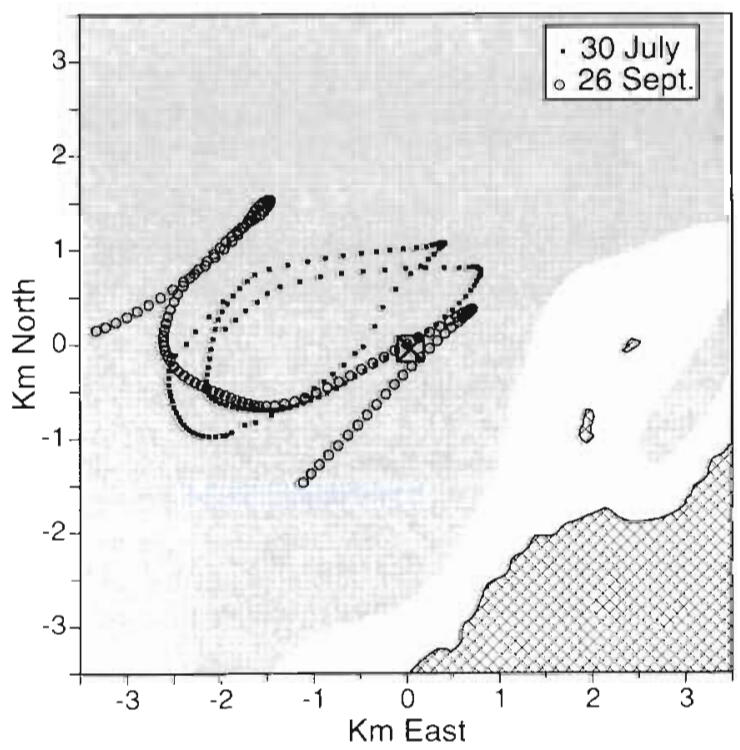

Fig. 7. Pathlines of flow at $1 \mathrm{~m}$.a.b. in Buzzards Bay (MA, USA), reconstructed from the velocity data in Fig. 3 and assuming a uniform flow field. Paths for 30 July and 26 September begin at 00:00 and 04:00 h, respectively, and both paths pass the field site (marked $\mathrm{X}$ ) at the time of final sampling (see 'Flood' tide sampling times on Fig. 3). Gray area indicates the central silty region of the bay, after Moore (1963). The 2 small Weepecket Islands, as well as a portion of Naushon Island marking the eastern boundary of the bay, are in the lower right corner 
and functional groups, with generally consistent results between days (Figs. 8 \& 9). All groups showed significant vertical gradients of concentration in the sediment, but most yielded statistically uniform profiles in the water column (with the exception on $30 \mathrm{July}$ of heterotrophic nanoflagellates [HNan] and a nonsignificant trend in scuticociliates, Table 2). Cell concentrations were generally higher on 30 July, when water temperature was greater.

Profiles of HNan in both the sediment and BBL showed significant differences among tidal stages on 30 July (Fig. 8A, Tables $2 \& 3$ ). Compared to slack tide, concentrations during tidal exchange were elevated by as much as $112 \%$ in the bottom $5 \mathrm{~cm}$ of the BBL and reduced by as much as $39 \%$ in the top $0.2 \mathrm{~cm}$ of sediment. Surficial sediment on 26 September also showed a significant difference of $40 \%$ between flood and slack low tide (Fig. 9A, Tables $2 \& 3$ ). These patterns are consistent with cells having resuspended from surficial sediment to a narrow zone above the SWI during tidal exchange.

In contrast to HNan, profiles of pigmented nanoflagellates (PNan) and of pennate diatoms were not significantly different among tidal stages in either the BBL or the sediment (Figs. 8B,C \& 9B,C, Table 2). On 30 July, however, there were nonsignificant trends of differences among tidal stages for PNan in the BBL and of a tidal stage $x$ depth interaction for diatoms in the sediment (Table 2 ).

Profiles of scuticociliates (mostly Uronema) showed patterns similar to those of HNan, with significant differences among tidal stages in both the sediment and BBL for both sampling dates (Figs. 8D \& 9D, Tables 2 \& 3). Compared to slack tide, concentrations during tidal exchange were elevated by as much as $356 \%$ at
Table 3. Bonferroni-adjusted p-values of pairwise multiple comparisons following ANOVA analyses of sedimentary data in Table 2. All pairwise comparisons (tidal stage by depth) were calculated simultaneously, but results are shown only comparing among tidal stages in the 0.0-0.2 cm sections. Within no other depth section was there a significant pairwise difference among tidal stages. 'Statistically significant at an overall $\alpha=0.05$

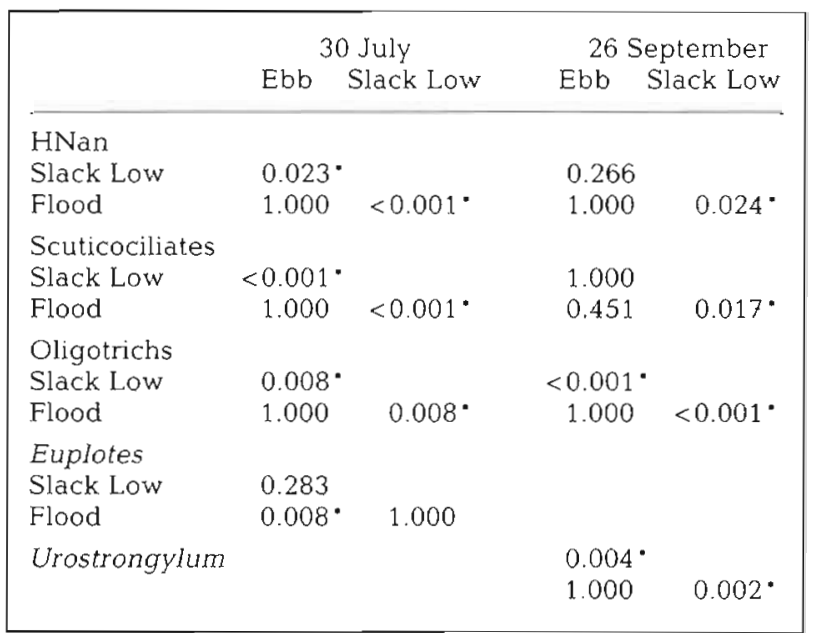

$1 \mathrm{~cm}$ above the bed (and present at higher elevations where no scuticociliates were found during slack tide) and reduced by as much as $63 \%$ in the top $0.2 \mathrm{~cm}$ of sediment. These data are also consistent with cells having resuspended from surficial sediment to the BBL during tidal exchange.

Other ciliate taxa yielded differing results. Oligotrichs on both dates were found consistently in the BBL, with no differences among tidal stages, but only during slack tide were they in the sediment (Figs. $8 \mathrm{E}$ $\&$ 9E, Tables 2 \& 3). (Grouped into our category of

Table 2. p-values from ANOVA analyses on protistan concentration profiles (Figs. 8 \& 9). Sedimentary data were run as 2 -way repeated measures ANOVA with depth as the repeated variable in each of 3 replicate cores. Boundary-layer data were run as 2 -way randomized block ANOVA using the means shown in Fig. 8. - Statistically significant at $\alpha=0.05$. HNan: heterotrophic nanoflagellates; PNan: pigmented nanoflagellates

\begin{tabular}{|c|c|c|c|c|c|c|c|c|c|}
\hline & \multicolumn{2}{|c|}{ Flagellates } & \multirow{2}{*}{$\begin{array}{l}\text { Diatoms } \\
\text { Pennate }\end{array}$} & \multicolumn{6}{|c|}{ Ciliates } \\
\hline & HNan & PNan & & $\begin{array}{l}\text { Scutico- } \\
\text { ciliates }\end{array}$ & $\begin{array}{l}\text { Oligo- } \\
\text { trichs }\end{array}$ & Euplotes & $\begin{array}{l}\text { Urostron- } \\
\text { gylum }\end{array}$ & $\begin{array}{l}\text { Sticho- } \\
\text { tricha }\end{array}$ & $\begin{array}{l}\text { Karyo- } \\
\text { relictids }\end{array}$ \\
\hline \multicolumn{10}{|l|}{$30 \mathrm{July}$ sediment } \\
\hline Tidal Stage & $0.016^{\circ}$ & 0.536 & 0.337 & $0.006^{\circ}$ & 0.079 & 0.118 & 0.559 & 0.422 & 0.430 \\
\hline Depth & $<0.001^{\circ}$ & $<0.001$ & $<0.001^{\circ}$ & $<0.001^{\circ}$ & $0.024^{\circ}$ & $<0.001^{\circ}$ & $<0.001^{\circ}$ & 0.415 & $<0.001^{\circ}$ \\
\hline Tidal Stage $\times$ Depth & $0.002^{\circ}$ & 0.843 & 0.057 & $<0.001^{\circ}$ & $0.010^{\circ}$ & $0.029^{\circ}$ & 0.696 & 0.455 & 0.496 \\
\hline \multicolumn{10}{|l|}{30 July boundary layer } \\
\hline Tidal Stage & $0.028^{\circ}$ & 0.053 & 0.102 & $0.015^{\circ}$ & 0.164 & 0.132 & & & \\
\hline Height & 0.081 & 0.939 & 0.110 & $0.041^{\circ}$ & 0.819 & 0.455 & & & \\
\hline \multicolumn{10}{|l|}{26 September sediment } \\
\hline Tidal Stage & 0.809 & 0.141 & 0.729 & $0.033^{\circ}$ & $0.027^{\circ}$ & 0.506 & $0.028^{\circ}$ & 0.824 & 0.912 \\
\hline Depth & $<0.001^{\circ}$ & $<0.001$ & $<0.001^{\circ}$ & $<0.001^{\bullet}$ & $0.003^{\circ}$ & $<0.001$ & $<0.001^{\circ}$ & $<0.001^{\circ}$ & $<0.001^{\circ}$ \\
\hline Tidal Stage $\times$ Depth & $0.009^{\circ}$ & 0.281 & 0.956 & 0.059 & $0.001^{\circ}$ & 0.673 & $0.005^{\circ}$ & 0.972 & 0.968 \\
\hline
\end{tabular}



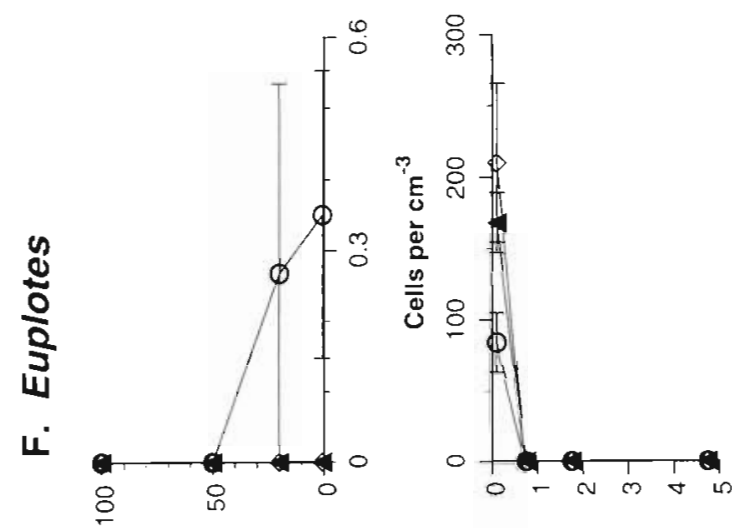

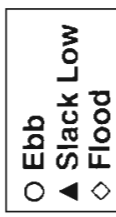

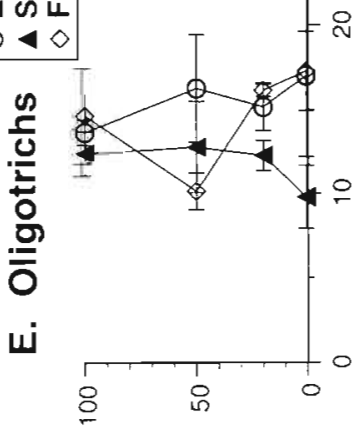

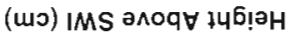
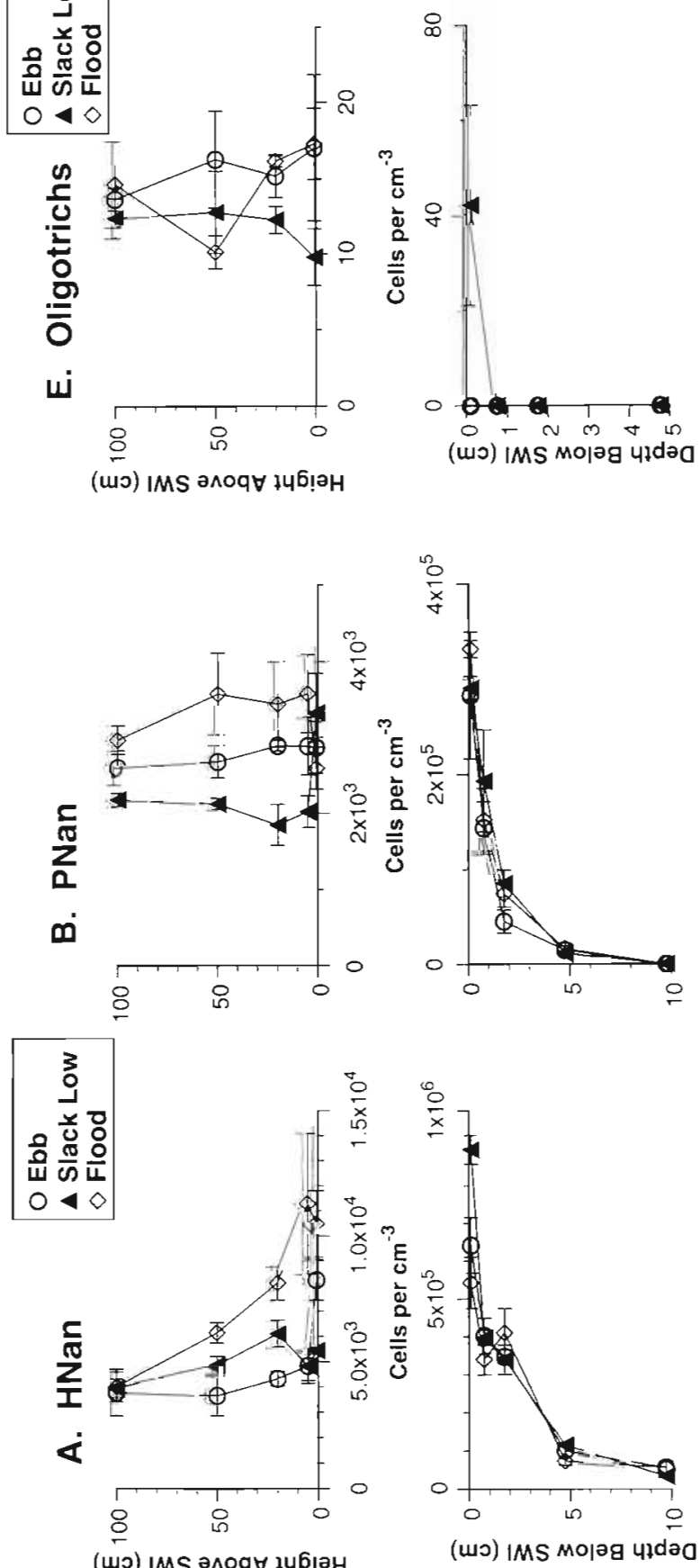
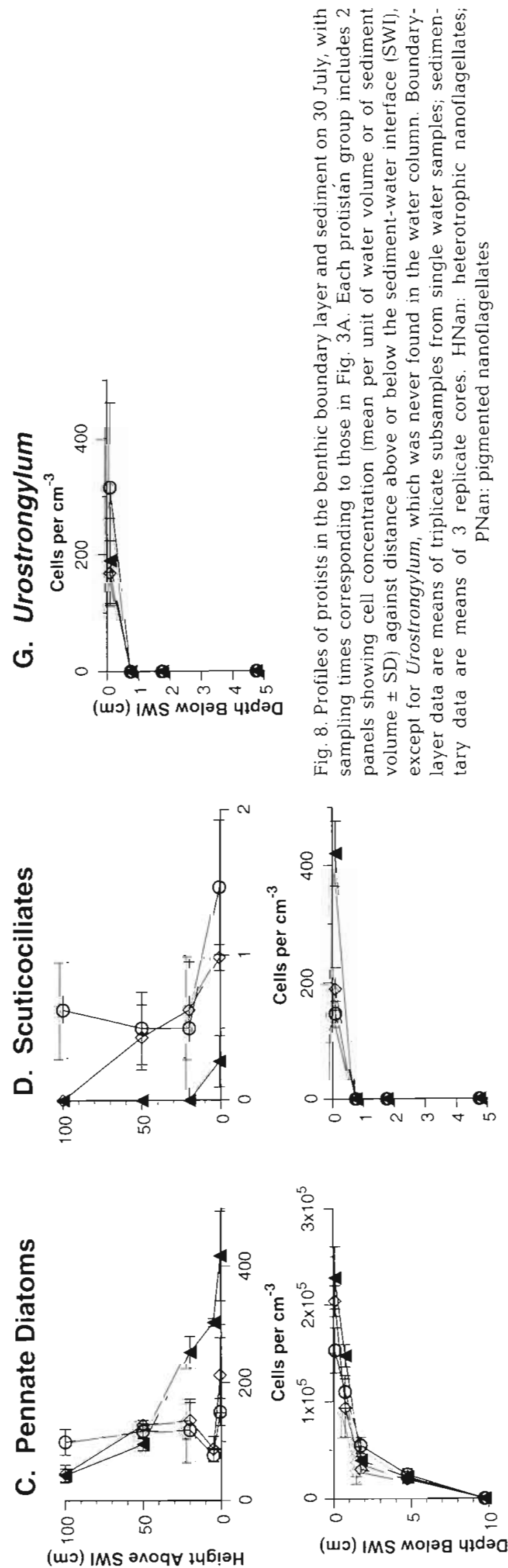

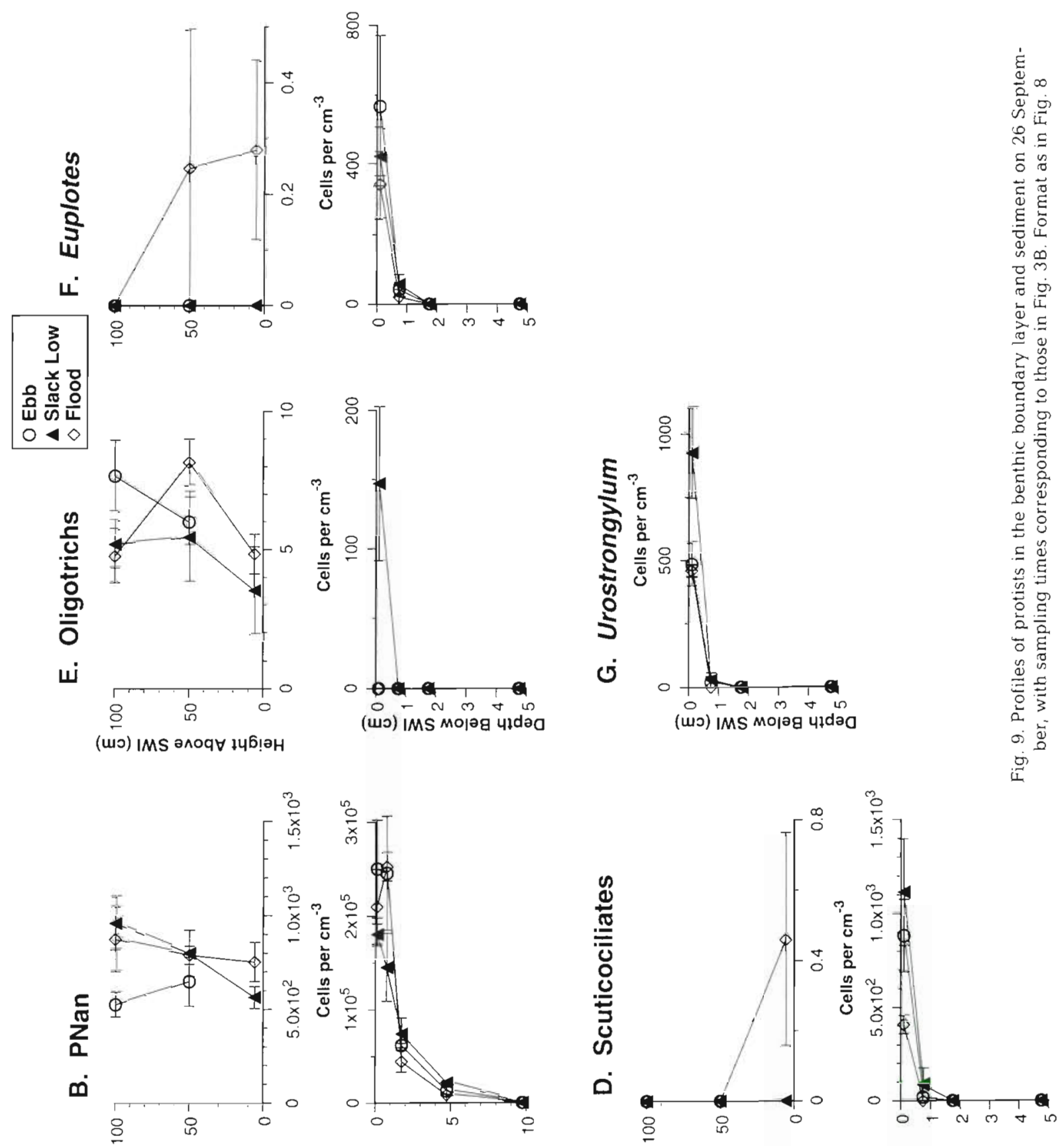

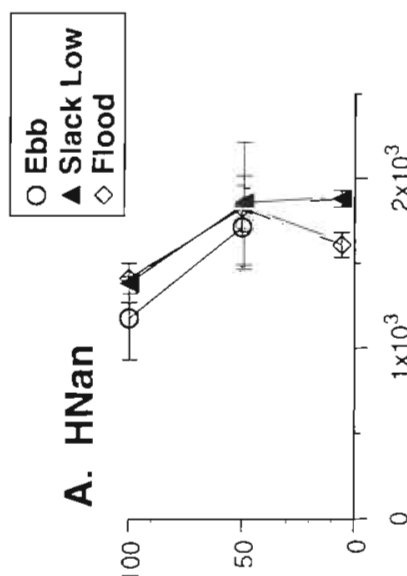

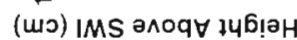

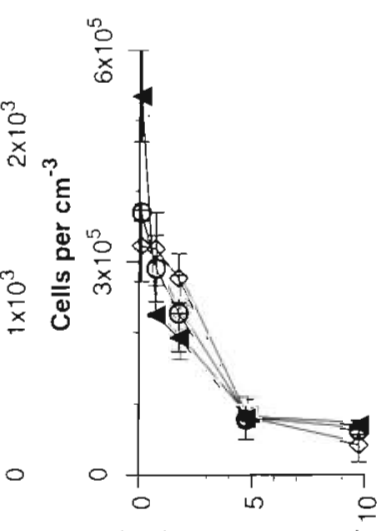

(யง) IMS Moləg पIdə0

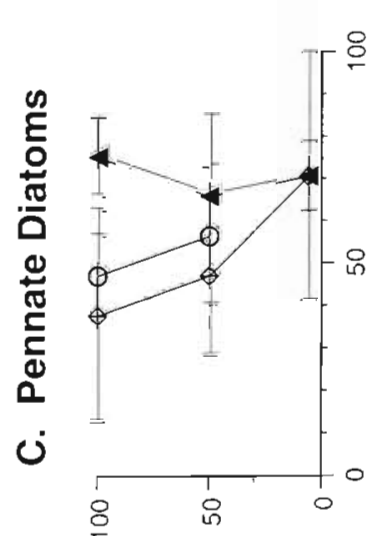

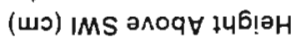

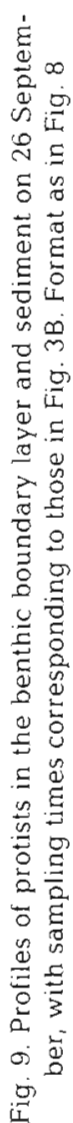

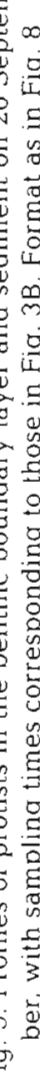


oligotrichs were at least 4 species of Oligotrichina and a Tintinnopsis; at least 2 of these species of Oligotrichina were found in the sediment.) The hypotrich Euplotes showed the opposite pattern: consistent presence in surficial sediment, but presence in the BBL only during some periods of tidal exchange (Figs. 8F \& 9F, Tables 2 \& 3). Other abundant ciliates, such as karyorelictids and other hypotrichs including Urostrongylum and Stichotricha, were found exclusively in the sediment at all times, with concentrations in the top $0.2 \mathrm{~cm}$ up to 315 cells $\mathrm{cm}^{-3}, 925$ cells $\mathrm{cm}^{-3}$, and 63 cells $\mathrm{cm}^{-3}$, respectively. Of these latter taxa, only Urostrongylum on 26 September showed significant differences among tidal stages, with concentrations in the top $0.2 \mathrm{~cm}$ of sediment during tidal exchange reduced by as much as $50 \%$ compared to slack low tide (Figs. 8G \& 9G, Tables $2 \& 3$ ). (Data for karyorelictids and Stichotricha are not shown.)

The total number of cells and amount of particulate material resuspended was estimated by several different methods (Table 4). The measured depletion of cells in the top $0.2 \mathrm{~cm}$ of sediment during tidal exchange suggested that order $10^{8}$ flagellates $\mathrm{m}^{-2}$ and $10^{5}$ to $10^{6}$ ciliates $\mathrm{m}^{-2}$ were resuspended. Estimates of cell

Table 4. Numbers of cells resuspended, calculated from both sedimentary and boundary-layer profiles. Sedimentary calculations were made only for those protists with significant pairwise differences between slack tide and tidal exchange (Table 3), and used only data from the $0.0-0.2 \mathrm{~cm}$ depth sections. Boundary-layer calculations were made only for those protists with a significant difference among tidal stages on 30 July (Table 2), except for Euplotes, which was only found in the boundary layer during tidal exchange. Boundary-layer calculations were integrated over the bottom $100 \mathrm{~cm}$ (see Figs $8 \& 9$ ), and in the case of HNan only comparing flood vs low tides

\begin{tabular}{|c|c|c|}
\hline & $\begin{array}{l}\text { Resuspension } \\
\text { calculated from } \\
\text { sedimentary } \\
\text { profiles } \\
\left(\text { cells m } \mathrm{m}^{-2}\right)\end{array}$ & $\begin{array}{l}\text { Observed } \\
\text { addition } \\
\text { to boundary } \\
\text { layer during } \\
\text { tidal exchange } \\
\left(\text { cells } \mathrm{m}^{-2}\right)\end{array}$ \\
\hline \multicolumn{3}{|l|}{ HNan } \\
\hline $\begin{array}{l}30 \mathrm{Jul} \\
26 \mathrm{Sep}\end{array}$ & $\begin{array}{c}5.1 \times 10^{8}-7.1 \times 10^{8} \\
4.2 \times 10^{8}\end{array}$ & $1.7 \times 10^{9}$ \\
\hline \multicolumn{3}{|c|}{ Scuticociliates } \\
\hline $\begin{array}{l}30 \mathrm{Jul} \\
26 \mathrm{Sep}\end{array}$ & $\begin{array}{c}4.6 \times 10^{5}-5.5 \times 10^{5} \\
1.4 \times 10^{6}\end{array}$ & $2.7 \times 10^{5}-5.5 \times 10^{5}$ \\
\hline \multicolumn{3}{|c|}{ Oligotrichs } \\
\hline 30 Jul & $8.4 \times 10^{4}$ & \\
\hline 26 Sep & $2.9 \times 10^{5}$ & \\
\hline \multicolumn{3}{|c|}{ Euplotes } \\
\hline $30 \mathrm{Jul}$ & & $6.2 \times 10^{4}$ \\
\hline 26 Sep & & $1.3 \times 10^{5}$ \\
\hline \multicolumn{3}{|c|}{ Urostrongylum } \\
\hline 26 Sep & $8.8 \times 10^{5}-9.3 \times 10^{5}$ & \\
\hline
\end{tabular}

resuspension by integrating $\mathrm{BBL}$ profiles were less reliable because of the lack of true replicates, but for HNan and scuticociliates the 2 methods gave roughly similar values (within a factor of 1 to 3 , Table 4), suggesting that the disappearance of cells from surficial sediment was approximately accounted for by their appearance in the BBL. A notable exception to this balance was Urostrongylum, which was reduced in the surficial sediment during tidal exchange on 26 September but was not found in elevated abundances either elsewhere in the sediment or in the BBL.

Assuming that cells were uniformly distributed throughout the top $0.2 \mathrm{~cm}$ of sediment, the changes in cell concentrations between tidal stages indicated that sediment was resuspended to a depth of 0.079 to $0.2 \mathrm{~cm}$. Using the mass of sediment measured in the top $0.2 \mathrm{~cm}$ from porosity samples, this erosion depth suggests that 131 to $333 \mathrm{~g}$ sediment $\mathrm{m}^{-2}$ was eroded.

\section{DISCUSSION}

\section{Material resuspension}

The tidal periodicity in turbidity is consistent with previous studies of material resuspension in Buzzards Bay (Rhoads 1973, Rhoads et al. 1975, Roman \& Tenore 1978). Rhoads (1973) described a turbid layer extending $3 \mathrm{~m}$ or more above bottom where suspended solids reached a maximum of 10 to $35 \mathrm{mg} \mathrm{l}^{-1}$ (cf. Figs. 4 \& 5). $\mathrm{He}$ also found that near-bottom turbidity peaked around slack tide, due to sinking of the resuspended load (cf. Figs. 2, 3), as did Eisma et al. (1994) in the Elbe estuary (Germany). For near-bottom water to become clearer during tidal exchange, erosion must be limited to a thin veneer of quickly eroded flocculent material at the SWI that overlies more erosion-resistant sediment; otherwise, continual resuspension during tidal exchange would cause maximal near-bottom turbidity to occur during peak flow. Such floc erosion, or 'Type I' erosion, has been well described and modeled with an exponentially decreasing erosion rate during constant flow and a direct relationship between depth and bed shear strength (Amos et al. 1992). The changes we measured in sedimentary cell concentrations suggested that $\leq 0.2 \mathrm{~cm}$ of sediment was likely to have eroded.

Our calculated mass erosion of 131 to $333 \mathrm{~g}$ sediment $\mathrm{m}^{-2}$ is higher than the resuspension in Buzzards Bay reported by Roman \& Tenore $\left(1978 ; 80 \mathrm{~g} \mathrm{~m}^{-2}\right.$, calculated from their POC resuspension and assuming $2.5 \%$ POC content in the sediment, Banta et al. 1995). However, our erosion depth calculated from cell profiles would be an overestimate if cells were concentrated at the SWI rather than uniformly distributed in the top $0.2 \mathrm{~cm}$ of sediment. 


\section{Specificity of protistan resuspension}

The protistan communities of the BBL and surficial sediment displayed taxon-specific and functional group-specific responses to material resuspension. HNan, scuticociliates, oligotrichs, Euplotes, and Urotrongylum showed significant periodicities in their vertical distributions consistent with a cycle of resuspension and deposition. In contrast, PNan, pennate diatoms, karyorelictids, and Stichotricha maintained constant vertical profiles throughout tidal cycles.

Among those groups displaying periodicities, there was no direct evicience that they left the surficial sediment during tidal exchange by migrating downward, and in the cases of HNan and scuticociliates the disappearance of cells from surficial sediment was roughly balanced by increases in the BBL. Oligotrichs, Euplotes, and Urostrongylum only showed a significant flux out of either the sediment or the BBL (Table 4), with no corresponding change in the profile on the other side of the SWI. This discrepancy can be easily explained for oligotrichs and Euplotes because the expected increases in concentration on the other side of the interface would have been similar to or much less than the standard deviations of measured concentrations there, rendering them undetectable. In contrast, resuspended Urostrongylum should have been detectable in the BBL during tidal exchange, unless they instead migrated slightly downward in the sediment and were hidden from our sampling by being in the 0.2 to $0.5 \mathrm{~cm}$ depth range.

Taxon- and functional-group-specific resuspension can be further understood by considering behavioral adaptations. Flagellates and ciliates can be classified as tectic (those that crawl or glide on particle surfaces and may attach, particularly for feeding) or free swimmers in the water column or interstices of sediment (Patterson et al. 1989).

Tectic flagellate taxa tend to be predominantly heterotrophic (Patterson et al. 1989). If HNan are more commonly or more strongly associated with particles at the SWI than are PNan, this might partially explain why only HNan resuspended and deposited along with particulate matter. Although both HNan and PNan are abundant on marine snow in surface water (Caron et al. 1986), their relative numbers on resuspended BBL particles have not been measured. However, even if predominantly in pore water, the failure of PNan to resuspend as the SWI was eroded implies that they either live sufficiently below the erosional layer (i.e. > $0.1 \mathrm{~cm}$ deep) or migrate downward to this depth during tidal exchange.

Hypotrichs, generally (including Euplotes, Urostrongylum, and Stichotricha), and karyorelictids are tectic (Patterson et al. 1989). Many hypotrichs are epiben- thic, both swimming and using their cirri to crawl on sedimentary particles. Jonsson \& Johansson (1997) documented Euplotes moving between the SWI and BBL in a flume, and they suggested that cells use flow for dispersal and location of food patches. Our data on Euplotes and Urostrongylum might represent this behavior in the field, correlating with the periodicity of tidal currents, and perhaps it should be considered active emergence from the SWI. Karyorelictids are vermiform, a shape that might aid retention in the sediment, and these ciliates have not been reported in water samples (Patterson et al. 1989).

Scuticociliates are primarily swimmers, but they can rest on surfaces to suspension feed (Patterson et al. 1989). If loosely associated with the SWI, they might readily resuspend merely due to the shear stress of the flow. However, Burkovsky et al. (1983) found a scuticociliate to behaviorally migrate vertically through sands on a diel cycle. We can only speculate as to whether the emergence of scuticociliates from the sediment is partially behavioral. Because they are unassociated with particles in the water column, however, scuticociliates would be slow to deposit at slack tide unless they swim toward the sediment.

Oligotrichs are swimmers. Certain species have been found in both the plankton and benthos and are considered epibenthic (Fenchel \& Jonsson 1988), but we have found no direct evidence in the literature that any oligotrich migrates between the sediment and water column. Because they are not associated with particles, deposition into the sediment must be by downward swimming.

Groups that did not resuspend must either live below the erosional surface of the SWI, migrate to that depth during tidal exchange, or adhere to particles large enough to resist resuspension. The nonsignificant results for pennate diatoms contrast with numerous studies of benthic diatom resuspension (e.g. Baillie \& Welsh 1980, de Jonge \& van Beusekom 1995), although some benthic microalgae have been found to migrate a few $\mathrm{mm}$ downward from the SWI as flow speed increases, thus avoiding resuspension (Berninger \& Huettel 1997). Benthic diatoms and PNan at the Weepecket site might have similarly found a refuge from resuspension below the erosional depth.

\section{Ecological implications}

Our data reveal taxon-specific migratory links between the sedimentary and water column communities of heterotrophic protists. Movement of epibenthic cells between the sediment and water column has been documented previously in laboratory observations of ciliates (Jonsson \& Johansson 1997), and 
planktonic heterotrophic flagellates are known to deposit on the bed with sinking particles (Novitsky 1990, Caron 1991), but we know of no prior documentation of cyclical emergence and re-entry into sediment in the field. Those heterotrophic protists that regularly resuspend and deposit represent a functional group that is both planktonic and benthic, although we do not know if they are equally active in both habitats. Meiofauna enter the BBL, by both passive and active means, where they may feed (Suderman \& Thistle 1998) and benefit from advection for dispersal (Palmer 1988). Jonsson \& Johansson (1997) concluded from flume studies that Euplotes may also use the BBL for dispersal, and our data suggest that this phenomenon could be common for a variety of heterotrophic protists in the field.

The dynamics of heterotrophic-protistan resuspension might be complex, as is known for benthic diatom resuspension (de Jonge \& van den Bergs 1987, Blanchard et al. 1997). The taxonomic and functional-group specificity of resuspension that we observed might have been caused by differing threshold levels of bed shear stress for erosion, similar to the findings of Arfi \& Bouvy (1995) and Blanchard et al. (1997) for phytobenthos and bacteria. Different groups therefore could resuspend in succession as flow speed increases, and deposit in a different sequence (perhaps reversed) as flow decelerates. The total number of taxa that exchanges between the benthic and planktonic communities could therefore vary with maximal flow speed during the lunar cycle (e.g, spring tides vs neap tides), as well as varying among habitats that differ in flow regime, sedimentary grain-size distribution or cohesiveness.

Periodic resuspension might alter not only the community structures of the plankton and benthos but also trophic interactions, feeding rates, and growth rates. We have documented heterotrophic protists as being abundant near the bed in a subtidal BBL, and they are likely integral to the food-web structure there. The BBL is a region of distinctly high bacterial abundances and growth rates compared to other water-column depths, and resuspension enhances bacterial cell size and possibly growth rates (Wainright 1987, Ritzrau \& Graf 1992, Ritzrau et al. 1997). Resuspended flagellates and ciliates are therefore exposed to an abundant and actively growing food resource. Concentrations of bacteria and microalgae may be lower in the BBL than in surficial sediment, as we found here, which could result in lowered feeding rates, but resuspended protists might benefit from exposure to a different community assemblage of prey species. However, resuspension also exposes protists to zooplankton predators. Periodic alterations of trophic interactions may thus be complex.
Feeding rates might also be influenced by resuspension and near-bottom flow via the direct effects of fluid shear on feeding mechanics (Shimeta et al. 1995). As cells are resuspended or deposited, they pass through regions with differing flow characteristics. Flow within sedimentary pore space is greatly restricted, whereas at the SWI cells experience strong shear in the viscous sublayer (with shear rate = $u^{2} / 0.01$, Caldwell \& Chriss 1979). Maximal shear rates in the viscous sublayer at our site therefore reached order $10^{2} \mathrm{~s}^{-1}$, assuming that a sublayer was maintained. Cells suspended in the turbulent BBL experience a vertical gradient of shear rate; calculated maximal values at our site ranged from $2 \mathrm{~s}^{-1}$ at $1 \mathrm{~m} . \mathrm{a} . \mathrm{b}$. to $19 \mathrm{~s}^{-1}$ at $1 \mathrm{~cm}$ (following equations in Shimeta \& Jumars 1991, Shimeta et al. 1995). For comparison, Shimeta et al. (1995) found that shear rates of only 0.1 to $10 \mathrm{~s}^{-1}$ were required to significantly enhance or suppress feeding rates of certain heterotrophic protists compared to feeding rates in still water. Therefore, feeding rates could be accelerated or reduced as cells move among the sedimentary and BBL habitats, and the division of time spent among the different habitats might impact growth rates. Taxa that benefit from ambient shear might experience the greatest feeding rates at the SWI, although they could be most susceptible to periodic erosion.

Acknowledgements. We are greatly indebted to C. A. Butman and D. A. Caron for advice and use of lab space and equipment, R. Geyer and R. Wheatcroft for advice, R. Geyer, A. Williams, T. Morrison, B. Keafer, L. Mullineaux, and B. Conolly for loaning and/or assisting with field instruments; D. Olmsted, captain of the RV 'Asterias'; V. Starczak, A. Frese, L. Chan, D. Moran, B. Keys, and B. Lancaster for assistance in the field and/or lab; V. Starczak for advice on statistics; and 3 anonymous reviewers for comments that improved the manuscript. This work was supported by a WHOI Postdoctoral Scholarship, a grant from the WHOI Rinehart Coastal Research Center, and NSF grant OCE-9711441 (all to J. Shimeta). WHOI contribution 9719.

\section{LITERATURE CITED}

Alongi DM (1990) Abundances of benthic microfauna in relation to outwelling of mangrove detritus in a tropical coastal region. Mar Ecol Prog Ser 63:53-63

Amos CL, Grant J, Daborn GR, Black K (1992) Sea carousela benthic, annular flume. Estuar Coast Shelf Sci 34: $557-577$

Arfi R, Bouvy M (1995) Size, composition and distribution of particles related to wind-induced resuspension in a shallow tropical lagoon. J Plankton Res 17:557-574

Baillie PW, Welsh BL (1980) The effect of tidal resuspension on the distribution of intertidal epipelic algae in an estuary. Estuar Coast Mar Sci 10:165-180

Bak RPM, Nieuwland G (1989) Seasonal fluctuations in benthic protozoan populations at different depths in marine sediments. Neth J Sea Res 24:37-44 
Banta GT, Giblin AE, Hobbie JE, Tucker J (1995) Benthic respiration and nitrogen release in Buzzards Bay, Massachusetts. J Mar Res 53:107-135

Berninger UG, Huettel M (1997) Impact of flow on oxygen dynamics in photosynthetically active sediments. Aquat Microb Ecol 12:291-302

Blanchard GF, Sauriau PG, Cariou-Le Gall V, Gouleau D. Garet MJ, Olivier F (1.997) Kinetics of tidal resuspension of microbiota: testing the effects of sediment cohesiveness and bioturbation using flume experiments. Mar Ecol Prog Ser 151:17-25

Burkovsky IV, Azovsky AI, Molibova NN (1983) Diurnal vertical migration of White Sea psammophilous ciliates. Zool Zh 62:944-947

Caldwell DR, Chriss TM (1979) The viscous sublayer at the sea floor. Science 205:1131-1132

Carey PG (1992) Marine interstitial ciliates. Chapman \& Hall, London

Caron DA (1991) Heterotrophic flagellates associated with sedimenting detritus. In: Patterson DJ, Larsen J (eds) The biology of free-living heterotrophic flagellates. Clarendon Press, Oxford, $p 77-92$

Caron DA, Davis PG, Madin LP, Sieburth JMcN (1986) Enrichment of microbial populations in macroaggregates (marine snow) from surface waters of the North Atlantic. $J$ Mar Res 44:543-565

de Jonge VN, van Beusekom JEE (1992) Contribution of resuspended microphytobenthos to total phytoplankton in the Ems estuary and its possible role for grazers. Neth $\mathrm{J}$ Sea Res 30:91-105

de Jonge VN, van Beusekom JEE (1995) Wind-and tideinduced resuspension of sediment and microphytobenthos from tidal flats in the Ems estuary. Limnol Oceanogr 40: $766-778$

de Jonge VN, van der Bergs J (1987) Experiments on the resuspension of esturaine sediments containing benthic diatoms. Estuar Coast Shelf Sci 24:725-740

Eisma D, Chen S, Li A (1994) Tidal variations in suspended matter floc size in the Elbe river and Dollard estuaries. Neth J Aquat Ecol 28:267-274

Epstein SS (1995) Simultaneous enumeration of protozoa and micrometazoa from marine sandy sediments. Aquat Microb Ecol 9:219-227

Fenchel T, Jonsson PR (1988) The functional biology of Strombidium sulcatum, a marine oligotrich ciliate (Ciliophora, Oligotrichina). Mar Ecol Prog Ser 48:1-15

Fuller CM, Butman CA (1988) A simple technique for finescale, vertical sectioning of fresh sediment cores. J Sedim Petrol 58:763-768

Hondeveld BJM, Nieuwland G, van Duyl FC. Bak RPM (1994) Temporal and spatial variations in heterotrophic nanoflage:llate abundance in North Sea sediments. Mar Ecol Prog Ser 109:235-243

Jonsson PR, Johansson M (1997) Swimming behaviour, patch exploitation and dispersal capacity of a marine benthic ciliate in flume flow. J Exp Mar Biol Ecol 215:135-153

Moore JR (1963) Bottom sediment studies, Buzzards Bay, Massachusetts. J Sedim Petrol 33:511-558

Novitsky JA (1990) Protozoa abundance, growth, and bacterivory in the water column, on sedimenting particles, and in the sediment of Halifax Harbor. Can J Microbiol 36: $859-863$

Palmer MA (1988) Dispersal of marine meiofauna: a review and conceptual model explaining passive transport and active emergence with implications for recruitment. Mar Ecol Prog Ser 48:81-91

Patterson DJ, Larsen J, Corliss Jo (1989) The ecology of het- erotrophic flagellates and ciliates living in marine sediments. Prog Protistol 3:185-277

Porter KG, Feig YS (1980) The use of DAPI for identifying and counting aquatic microflora. Limnol Oceanogr 25:943-948

Rhoads DC (1973) The influence of deposit-feeding benthos on water turbidity and nutrient recycling. Am J Sci 273: $1-22$

Rhoads DC, Tenore K, Browne M (1975) The role of resuspended bottom mud in nutrient cycles of shallow embayments. In: Cronin LE (ed) Estuarine Research, Vol 1. Academic Press, New York, p 563-579

Ritzrau W (1996) Microbial activity in the benthic boundary layer: small-scale distribution and its relationship to the hydrodynamic regime. J Sea Res 36:171-180

Ritzrau W, Graf G (1992) Increase of microbial biomass in the benthic turbidity zone of Kiel Bight after resuspension by a storm event. Limnol Oceanogr 37:1081-1086

Ritzrau W, Thomsen L, Lara RJ, Graf G (1997) Enhanced microbial utilization of dissolved amino acids indicates rapid modification of organic matter in the benthic boundary layer. Mar Ecol Prog Ser 156:43-50.

Roman MR (1978) Tidal resuspension in Buzzards Bay, Massachusetts. I1. Seasonal changes in the size distribution of chlorophyll, particel concentration, carbon and nitrogen in resuspended particulate matter. Estuar Coast Mar Sci 6: $47-53$

Roman MR (1980) Tidal resuspension in Buzzards Bay, Massachusetts, III. Seasonal changes of nitrogen and carbon:nitrogen ratios in seston and zooplankton. Estuar Coast Mar Sci 11:9-16

Roman MR, Tenore KR (1978) Tidal resuspension in Buzzards Bay, Massachusetts. I. Seasonal changes in the resuspension of organic carbon and chlorophyll a. Estuar Coast Mar Sci $6: 37-46$

Rowe GT, McNichol AP (1991) Carbon cycling in coastal sediments: estimating remineralization in Buzzards Bay, Massachusetts. Geochim Cosmochim Acta 55:2989-2991

Shimeta J, Jumars PA (1991) Physical mechanisms and rates of particle capture by suspension feeders. Oceanogr Mar Biol Annu Rev 29:191-257

Shimeta J, Jumars PA, Lessard EJ (1995) Influences of turbulence on suspension feeding by planktonic protozoa; experiments in laminar shear fields. Limnol Oceanogr 40: 845-859

Starink M, Bar-Gilissen MJ, Bak RPM, Cappenberg TE (1994\} Quantitative centrifugation to extract benthic protozoa from freshwater sediments. Appl Environ Microbiol 60: $167-173$

Sternberg RW (1968) Friction factors in tidal channels with differing bed roughness. Mar Geol 6:243-260

Suderman K, Thistle D (1998) Adult female harpacticoid copepods maintain their energy reserves by feeding while suspended during storms. Mar Ecol Prog Ser 164:245-252

Townsend DW, Mayer LM, Dortch Q. Spinrad RW (1992) Vertical structure and biological activity in the nepheloid layer of the Gulf of Maine. Cont Shelf Res 12:367-387

Wainright SC (1987) Stimulation of heterotrophic microplankton production by resuspended marine sediments. Science 238:1710-1712

Wainright SC (1990) Sediment-to-water fluxes of particulate material and microbes by resuspension and their contribution to the planktonic food web. Mar Ecol Prog Ser 62: $271-281$

Wheatcroft RA, Butman CA (1997) Spatial and temporal variability in aggregated grain-size distributions, with implicatınns for sediment dynamics. Cont Shelf Res 17 : $367-390$

Submitted: May 28, 1998; Accepted: October 9, 1998

Proofs received from author(s): February 5, 1999 